\title{
APLIKASI METODE SELF-POTENTIAL UNTUK MENGAMATI ALIRAN AIR TANAH DI JALAN PERDANA KOTA PONTIANAK, KALIMANTAN BARAT
}

\author{
Muhardi, Radhitya Perdhana, Kaharudin, Charles Billy Sirait, \\ Dwiki Nur Jayanto, Muhammad Soleh, Peni Aprilianti, Theresia Eva \\ Program Studi Geofisika Universitas Tanjungpura, Pontianak
}

Email korespondensi : $\underline{\text { muhardi@pyhsics.untan.ac.id }}$

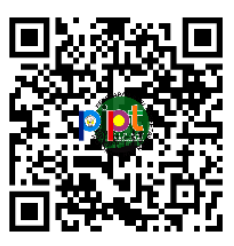

\begin{abstract}
Abstrak
Penelitian ini bertujuan untuk mengidentifikasi aliran air tanah bawah permukaan di sekitar Jalan Perdana, Kelurahan Bansir Laut, Kota Pontianak. Pengamatan aliran air tanah berguna untuk mengetahui lokasi yang berpotensi terdapat air tanah. Penelitian ini menggunakan metode selfpotential dengan mengaplikasikan 12 lintasan yang masing-masing mempunyai panjang $130 \mathrm{~m}$. Jarak antar lintasan sejauh $10 \mathrm{~m}$ dan jarak antar elektroda porous pot adalah $10 \mathrm{~m}$. Hasil penelitian menunjukkan bahwa variasi nilai potensial sebelum koreksi variasi harian yaitu $-36.44 \mathrm{mV}$ hingga $25.18 \mathrm{mV}$, sedangkan nilai potensial setelah koreksi variasi harian yaitu $-36.64 \mathrm{mV}$ hingga 25.86 $\mathrm{mV}$. Nilai potensial relatif tinggi berada di bagian barat dan timur, sedangkan nilai potensial relatif rendah berada di bagian tengah dari lokasi penelitian. Hasil penelitian juga menunjukkan bahwa air tanah diduga mengalir dari arah barat dan timur menuju ke bagian tengah dari lokasi penelitian.
\end{abstract}

Kata kunci: air tanah, aliran, jalan perdana, kota pontianak, self-potential

\section{PENDAHULUAN}

Air tanah merupakan salah satu sumber daya alam yang dapat dimanfaatkan untuk memenuhi ketersediaan air bersih dalam kehidupan sehari-hari. Jumlah air tanah yang melimpah dengan kualitas yang baik dapat dijadikan sebagai salah satu sumber air bersih. Meskipun ketersediaannya melimpah pada lapisan akuifer di bawah permukaan, namun diperlukan informasi tentang keberadaan air tanah tersebut agar dapat digunakan secara maksimal. Salah satu informasi yang dibutuh-kan masyarakat khususnya dalam pemanfaatan air tanah yaitu tentang aliran air tanah agar keberadaannya dapat teridentifikasi.

Air bersih di Kota Pontianak khususnya di sekitar Jalan Perdana, Kelurahan Bansir Laut, Kecamatan Pontianak Tenggara bersumber dari Perusahaan Daerah Air Minum (PDAM) Kota Pontianak. Ketersediaan air ini biasanya akan mengalami kendala pada saat musim kemarau. Umumnya, kendala tersebut berupa menurun-nya kualitas air, misalnya keadaan air yang mengalami perubahan rasa menjadi lebih payau atau bahkan asin. Diperlukan informasi mengenai sumber air bersih alternatif, salah satunya yaitu pemanfaatan air tanah yang dijadikan solusi terhadap permasalahan tersebut. Oleh sebab itu, perlu adanya penelitian terhadap sebaran aliran air tanah di Jalan Perdana, Kota Pontianak dengan menggunakan metode self-potential.

Metode geolistrik telah banyak digunakan dalam penyelidikan air tanah, misalnya untuk mengetahui keberadaan air tanah pada lapisan akuifer (Darsono, 2016), pola sebaran air tanah (Manrulu et al., 2018), dan pengaruh intrusi air laut pada air tanah (Muhardi et al., 2020). Informasi ini dapat dijadikan rujukan untuk pemanfaatan air tanah dalam memenuhi kebutuhan rumah tangga maupun industri. Salah satu metode geolistrik yang juga dapat digunakan untuk menganalisis kondisi aliran air tanah bawah permukaan yaitu metode self-potential (Arisalwadi et al., 2020).

Metode self-potential merupakan metode yang memanfaatkan potensial diri (alami) di bawah permukaan, smetode ini termasuk ke dalam metode pasif. Metode self-potential telah dimanfaatkan untuk 
mengeksplorasi sumber daya alam bawah permukaan, pergerakan air tanah (Nordiana et al., 2018), pergerakan tanah (Santoso et al., 2020), sebaran lindi (Rosid et al., 2012), aliran sungai bawah tanah (Hasan et al., 2018), kebocoran pada bendungan (Thanh et al., 2020), dan lain-lain. Aktivitas elektrokimia dan mekanik menyebabkan adanya potensial diri di permukaan (Reynolds, 1997). Penggunaan metode self-potential pada survei geofisika sangat sederhana (Telford et al., 1990) dan biaya yang dibutuhkan juga relatif lebih kecil.

Prinsip dari metode self-potential yaitu mengukur tegangan statis di permukaan bumi dengan memanfaatkan 2 buah elektroda porous pot atau elektroda berpori yang disambungkan terhadap multimeter (Cabusson et al., 2021). Tujuan dari penggunaan porous pot merupakan suatu cara untuk menghilangkan adanya efek polarisasi elektroda ketika pengukuran di lapangan (Telford et al., 1990). Metode ini sangat responsif dalam mengidentifikasi objek yang bersifat konduktif, misalnya mineral logam (Everett, 2013).

\section{METODOLOGI}

Penelitian dilakukan di Kota Pontianak khususnya di sekitar Jalan Perdana, Kelurahan Bansir Laut yang berada pada koordinat 004'15.86"S - 004'21.41"S dan $109^{0} 19^{\prime} 56.63$ 'E - $109^{0} 20{ }^{\prime} 1.98$ 'E. Pengukuran nilai potensial mengaplikasikan 12 Lintasan (L1, L2, L3, L4, L5, L6, L7, L8, L9, L10, L11, L12) dengan panjang masingmasing $130 \mathrm{~m}$. Pelaksanaan penelitian dilaksanakan selama tiga hari pada bulan Juni 2021. Desain dan lokasi pengukuran disajikan pada Gambar 1.

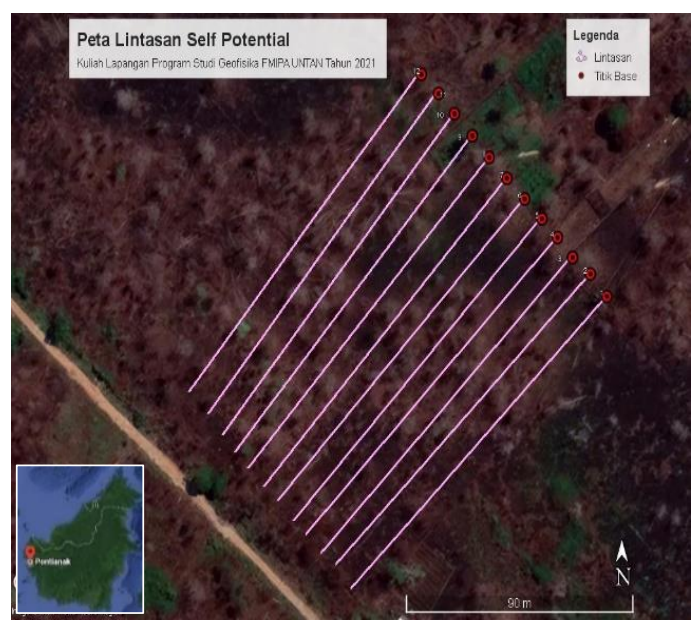

Gambar 1: Desain survei di lokasi penelitian

Penelitian ini menggunakan 10 elektroda porous pot dengan konfigurasi fixed base. Kelebihan dari konfigurasi ini adalah proses pengolahan data yang lebih sederhana sehingga pengukuran tidak memerlukan looping. Potensial pada titik pengukuran diukur dengan 1 buah elektroda porous pot yang berada pada titik acuan (base station) dan 1 buah elektroda porous pot lainnya berpindah-pindah sepanjang lintasan pengukuran pada jarak tetap. Konfigurasi fixed base membutuhkan kabel yang panjang karena 1 buah elektroda porous pot yang tetap berada di titik acuan dan 1 buah elektroda porous pot yang lain mengukur di titik pengukuran selanjutnya hingga ke titik maksimal yang telah ditentukan. Gambar 2 merupakan contoh pengukuran potensial menggunakan konfigurasi fixed base.

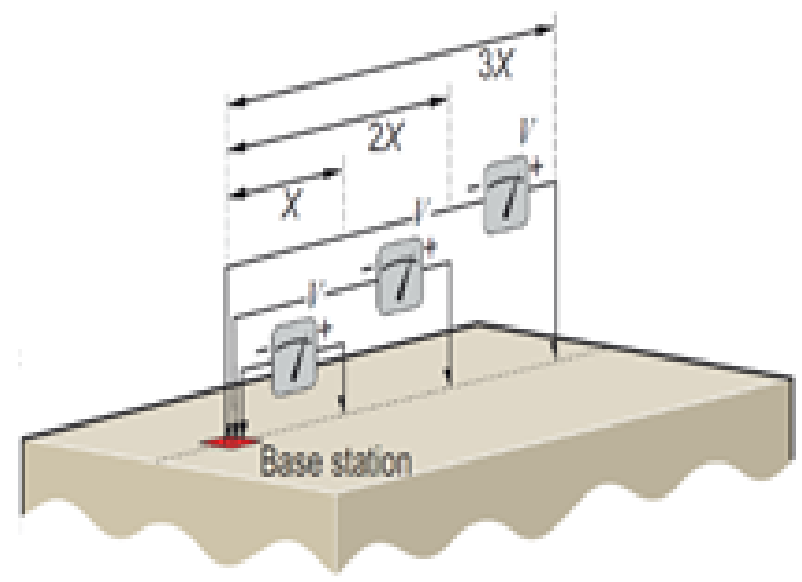

Sumber: (Dentith \& Mudge, 2014)

Gambar 2: Ilustrasi pengukuran potensial dengan konfigurasi fixed base 
Pengambilan data dilakukan dengan dua metode, yaitu berdasarkan fungsi posisi dan fungsi waktu. Pemanfaatan data potensial diri berdasarkan fungsi waktu dilakukan untuk mengoreksi data yang diperoleh berdasarkan fungsi posisi. Titik acuan tersebut berada pada luar area target survei yang dibuat sebagai tempat akuisisi data base. Pengukuran rover tersebut dilakukan sepanjang lintasan peng-ukuran dengan jarak yang telah ditentukan. Nilai potensial yang terdistribusi di setiap lintasan kemudian diplot pada area dengan luasan tertentu untuk menentukan aliran air tanah bawah permukaan di lokasi penelitian.

\section{HASIL DAN PEMBAHASAN}

Pengambilan data sebagai fungsi waktu dilakukan di luar area target survei dan digunakan sebagai tempat pengambilan data base. Hasil variasi potensial diri berdasarkan fungsi waktu dapat dilihat pada Gambar 3 . Pengukuran dilakukan selama 3 (tiga) hari. Data ini diperoleh setiap 2 menit dengan asumsi dapat mengoreksi nilai potensial yang diperoleh berdasarkan fungsi posisi.

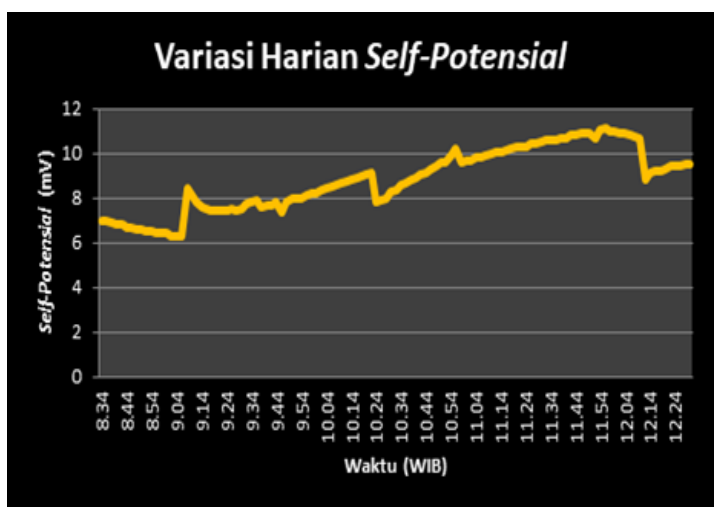

(a)

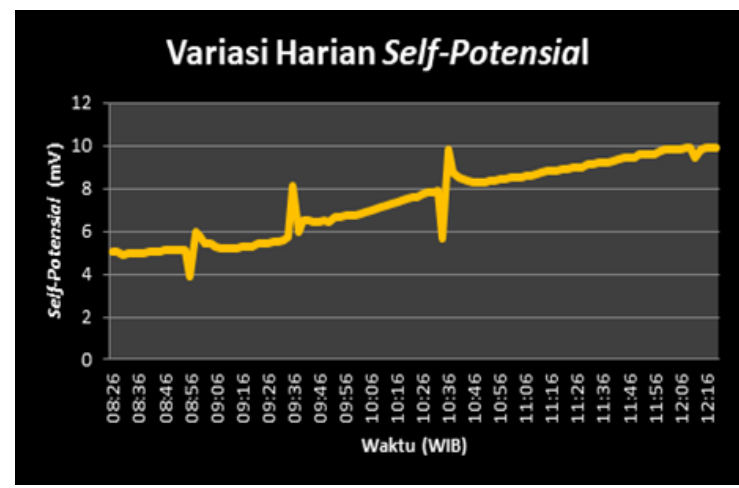

(b)

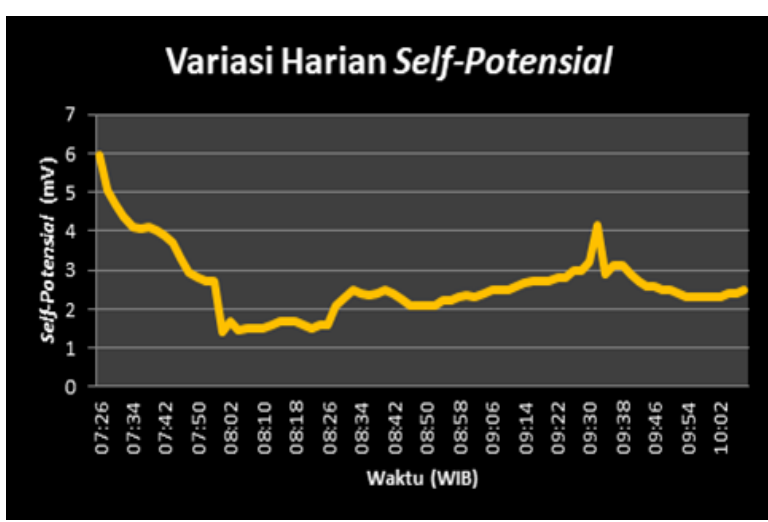

(c)

Gambar 3: Potensial diri (self potensial) variasi harian; (a) hari ke-1, (b) hari ke-2, dan (c) hari ke-3

Akuisisi data dengan fungsi posisi dilakukan sebanyak 12 lintasan. Panjang masing-masing lintasan sejauh $130 \mathrm{~m}$, jarak antar lintasan sejauh $10 \mathrm{~m}$ dan jarak antar elektroda porous pot sejauh $10 \mathrm{~m}$. Pada setiap lintasan dilakukan pengukuran terhadap 123 titik pengukuran potensial.

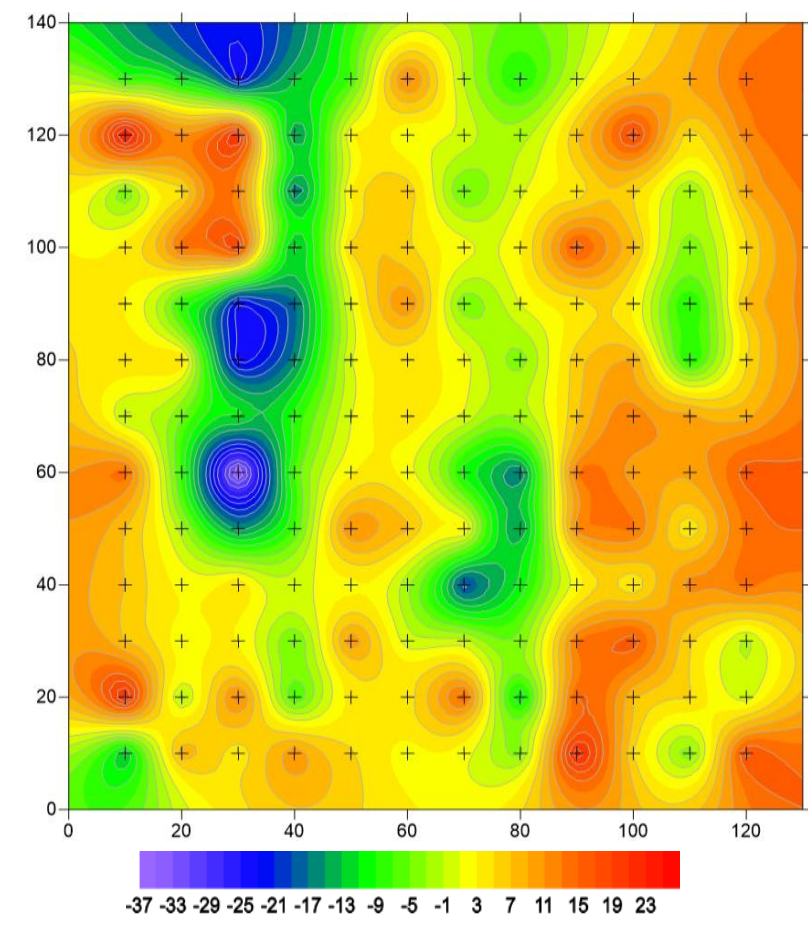

Gambar 4: Peta sebaran potensial diri sebelum dilakukan koreksi variasi harian 


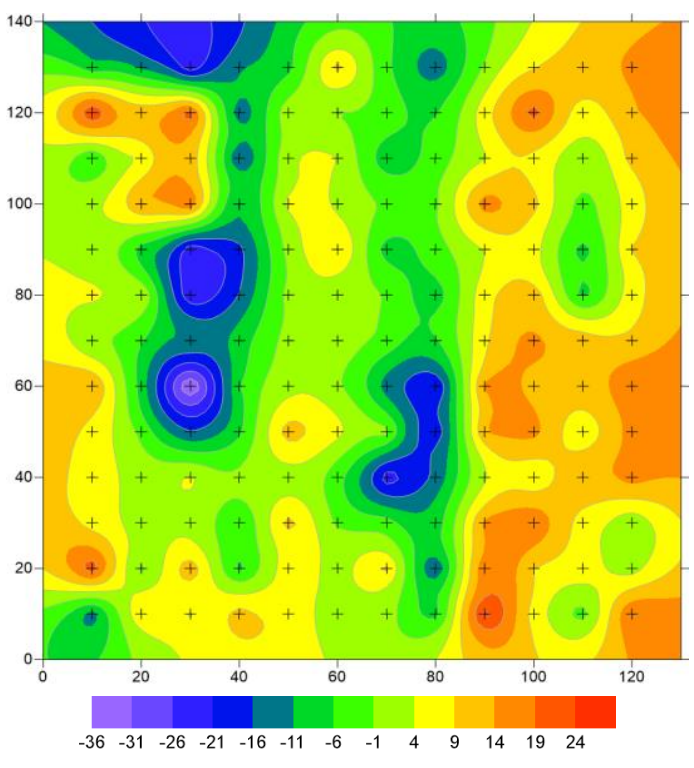

Gambar 5: Peta sebaran potensial diri setelah dilakukan koreksi variasi harian

Gambar 4 menunjukkan bahwa variasi nilai potensial sebelum koreksi variasi harian yaitu $-36.44 \mathrm{mV}$ hingga $25.18 \mathrm{mV}$. Pola sebaran nilai potensial berwarna biru merupakan nilai anomali yang kecil akibat adanya akumulasi aliran fluida atau air tanah di bawah permukaan. Sedangkan nilai potensial berwarna merah merupakan nilai anomali yang besar. Gambar 5 menunjukkan nilai potensial yang telah dilakukan koreksi variasi harian sehingga diperoleh nilai potensial sebesar $-36.64 \mathrm{mV}$ hingga 25.86 $\mathrm{mV}$.

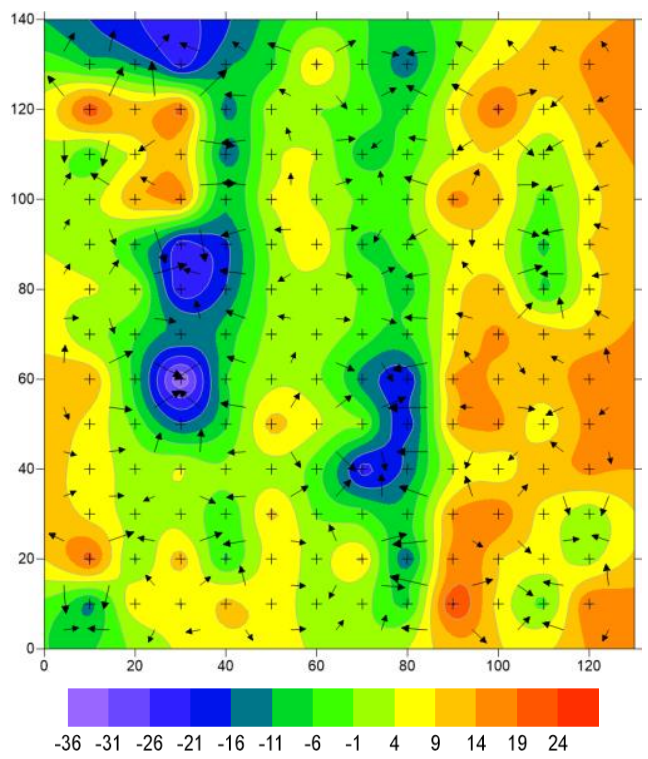

Gambar 6: Peta sebaran dan arah aliran fluida
Aliran fluida ditunjukkan dengan tanda panah hitam yang mempunyai arah tegak lurus terhadap bidang ekipotensial, sehingga dari sebaran nilai potensial dapat diinterpretasikan pola arah aliran fluida (Nordiana et al., 2018). Aliran air tanah diinterpretasi berasal dari potensial tinggi ke potensial rendah (Hasan et al., 2018). Gambar 6 menunjukkan nilai potensial relatif tinggi berada di bagian barat dan timur, sedangkan nilai potensial relatif rendah terdapat di bagian tengah dari lokasi penelitian. Dengan demikian, aliran air tanah di lokasi penelitian diduga cenderung mengalir dari arah barat dan timr menuju ke bagian tengah dari lokasi penelitian.

\section{KESIMPULAN}

Berdasarkan hasil penelitian dapat ditarik suatu kesimpulan bahwa variasi nilai potensial sebelum dilakukan koreksi sebesar -36.44 $\mathrm{mV}$ hingga $25.18 \mathrm{mV}$, sedangkan setelah dilakukan koreksi sebesar $-36.64 \mathrm{mV}$ hingga $25.86 \mathrm{mV}$. Sebaran potensial menunjukkan bahwa nilai potensial yang relatif tinggi berada di arah bagian barat dan timur, sedangkan nilai potensial yang relatif rendah berada di bagian tengah dari lokasi penelitian. Dengan demikian, air tanah diduga mengalir dari arah barat dan timur menuju ke bagian tengah dari lokasi penelitian.

\section{DAFTAR PUSTAKA}

Arisalwadi, M., Cahyani, R. S., Septiana, A. R., Rahmania, \& Sastrawan, F. D. (2020). Aplikasi Metode SelfPotential untuk Pemetaan Bawah Permukaan di Area Kampus ITK. Indonesian Physical Review, 3(3), 124-131.

Cabusson, S. B., Finizola, A., \& Grobbe, N. (2021). A practical Approach for SelfPotential Data Acquisition, Processing, and Visualization. Interpretation, 9(1), 1-21. 
Darsono. (2016). Identifikasi Akuifer Dangkal dan Akuifer Dalam dengan Metode Geolistrik (Kasus : di Kecamatan Masaran). Indonesian Journal of Applied Physics, 1(1), 4049.

Dentith, M., \& Mudge, S. (2014). Geophysics for the Mineral Exploration Geoscientist. Cambridge University Press.

Everett, M. E. (2013). Near-Surface Applied Geophysics. Cambridge University Press.

Hasan, M. F., Susilo, A., \& Sunaryo. (2018). Identification of Underground River Flow Pattern Using Self Potential (SP) and Resistivity Methods for Drought Mitigation at Druju, Sumbermanjing Wetan, Indonesia. Disaster Advances, 11(5), 25-31.

Manrulu, R. H., Nurfalaq, A., \& Hamid, D. (2018). Pendugaan Sebaran Air Tanah Menggunakan Metode Geolistrik Resistivitas Konfigurasi Wenner dan Schlumberger Di Kampus 2 Universitas Cokroaminoto Palopo. Jurnal Fisika Flux, 15(1), 612.

Muhardi, Faurizal, \& Widodo. (2020). Analisis Pengaruh Intrusi Air Laut terhadap Keberadaan Air Tanah di Desa Nusapati, Kabupaten Mempawah Menggunakan Metode Geolistrik Resistivitas. Indonesian Journal of Applied Physics, 10(2), 89-96.
Nordiana, M. M., Olugbenga, A. T., Saharudin, M. A., Nabila, S., \& Hidayah Ismail, N. El. (2018). The Application of 2-D Resistivity and Self Potential (SP) Methods in Determining the Water Flow. Journal of Physics: Conference Series, 995, $1-9$.

Reynolds, J. M. (1997). An Introduction to Applied and Environmental Geophysics. John Wiley \& Sons Ltd.

Rosid, S., Koesnodo, R. N., \& Nuridianto, P. (2012). Estimasi Aliran Air Lindi TPA Bantar Gebang Bekasi Menggunakan Metoda SP. Jurnal Fisika Unnes, 1(2), 54-59.

Santoso, B., Subagio, S., Hasanah, M. U., \& Suwarga, H. (2020). Investigation Estimating of Land Movement Using Methods of Electrical Resistivity Tomography and Self-Potential in Pasanggrahan Baru Area, South Sumedang. Jurnal Geologi dan Sumberdaya Mineral, 21(1), 33-44.

Telford, W. M., Geldart, L. P., \& Sheriff, R. E. (1990). Applied Geophysics (Second Edi). Cambridge University Press.

Thanh, L. D., Thai, N. C., Hung, N. M., Thang, N. C., \& Huong, L. T. T. (2020). Self-Potential Method for Detection of Water Leakage Through Dams. Earth Science Malaysia, 4(2), 152-155. 
Bidang Ilmu Pengetahuan Alam 